Journal of Southeast Asian

\title{
(Mis)Labeled: The Challenge of Academic Capital Formation for Hmong American High School Students in an Urban Setting
}

\author{
Anna Chiang \\ University of Michigan, chiangan@umich.edu \\ Joshua Fisher \\ University of Michigan, jpfishe@umich.edu \\ William Collins \\ University of Michigan, umceo@umich.edu \\ Marie Ting \\ University of Michigan, maript@umich.edu
}

Follow this and additional works at: https://docs.lib.purdue.edu/jsaaea

Part of the Bilingual, Multilingual, and Multicultural Education Commons

\section{Recommended Citation}

Chiang, Anna; Fisher, Joshua; Collins, William; and Ting, Marie (2015) "(Mis)Labeled: The Challenge of Academic Capital Formation for Hmong American High School Students in an Urban Setting," Journal of Southeast Asian American Education and Advancement. Vol. 10 : Iss. 1, Article 4.

DOI: $10.7771 / 2153-8999.1118$

Available at: https://docs.lib.purdue.edu/jsaaea/vol10/iss1/4

This document has been made available through Purdue e-Pubs, a service of the Purdue University Libraries. Please contact epubs@purdue.edu for additional information.

This is an Open Access journal. This means that it uses a funding model that does not charge readers or their institutions for access. Readers may freely read, download, copy, distribute, print, search, or link to the full texts of articles. This journal is covered under the CC BY-NC-ND license. 


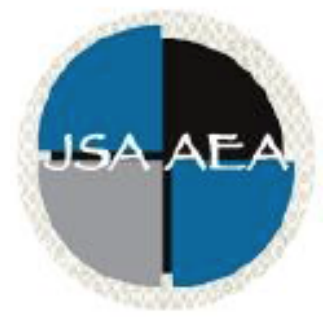

\title{
Journal of Southeast Asian American Education and Advancement www.JSAAEA.org
}

Volume 10 (2015)

\author{
(Mis)Labeled: The Challenge of Academic Capital Formation \\ for Hmong American High School Students in an Urban Setting
}

\author{
Anna Chiang, Joshua Fisher, William Collins, Marie Ting \\ University of Michigan
}

\begin{abstract}
The Model Minority Myth for Asians as a group disguises the challenges facing Hmong and other underrepresented Southeast Asian American groups. Using the theoretical framework of Academic Capital Formation (ACF), this qualitative study examines the implications of the Model Minority Myth by focusing on the experiences and educational challenges of Hmong American high school students in an urban setting in the Midwest. Results from this study alludes to a bimodal pattern of achievement amongst the Asian American Pacific Islander community, emphasizing the importance of increasing visibility for underrepresented Southeast Asians, such as Hmong Americans, with regards to access to higher education.
\end{abstract}

\section{Introduction}

Over the past several decades, access to higher education has taken on new meaning. After the passage of policies following the Brown v. Board of Education era, access meant increasing the opportunities for ethnic minorities to pursue higher education. In today's society, access has become rather complex. With the emerging shift in student demographics and a societal push for higher education institutions to be reflective of a growing and changing society, diversity has become an eminent topic of concern.

In particular, the Asian American and Pacific Islander (AAPI) community has been relegated to the periphery; this group's challenges to higher education access are often overlooked, considering that most policies and academic literature on higher education access for minority students focus primarily on the challenges of other underrepresented ethnic groups such as Latinos and African Americans (Cepeda, 2011). Moreover, the AAPI student "overrepresentation" in higher education reduces them to the labels of "Model Minorities," masking their educational challenges and limiting them in the discourse regarding diversity initiatives. 
Hmong Americans ${ }^{1}$ are a specific AAPI sub-population that is underrepresented in higher education. Using the theoretical framework of Academic Capital Formation (ACF), this study examines the related implications of the Model Minority Myth (MMM) by focusing on the experiences and educational challenges of a group of Hmong American high school students attending an urban school in a low-income neighborhood of a major city in the Midwest. We will explore the factors that influence their decision of whether or not to pursue higher education. More specifically, this study explores the following questions:

\section{How do Hmong American students develop Academic Capital Formation?}

2. What are their experiences with the Model Minority Myth stereotype about AAPIs and how does it impact their desire to pursue a higher education?

3. What lessons can be drawn from the research participants about college access for underrepresented AAPI students (such as Hmong American students) that can inform policy and practices related to access in higher education?

We conducted interviews and focus groups with seven Hmong American high school students specifically focusing on their experiences with growing up in their neighborhoods, with the Hmong community, in their schools, and their ideas about college. The interviews were examined with the goal of discerning the ACF of the students in relation to their perception of higher education attainment. As we interacted with the students, we began to gain an appreciation for the challenges students faced with respect to their educational attainment aspirations and as a result, endeavored to learn more from them about their goals and circumstances so that subsequent efforts might more appropriately address their needs. In the ensuing sections, background will be provided to discuss the historical context of Hmong Americans, their educational experiences in the United States, as well as the framework used in our analyses. Following, we will discuss our research methods, findings, and close with our recommendations.

\section{Background}

AAPIs are often homogenized into one singular racial group, aggregated together with no distinctions between national origin, history, socioeconomic background, immigration status, language(s) spoken, or parents' educational levels (Teranishi, Ceja, Antonio, Allen, \& McDonough, 2004; Wing, 2007;). However, according to the 2010 U.S. Census Bureau, the AAPI racial category consists of 48 different ethnic groups that occupy positions along the full range of the socioeconomic spectrum, from the poor and under-privileged, to the affluent and highly-skilled ("CARE," 2011; Cepeda, 2011). Lew, Chang, \& Wang (2005) highlight the fact that the AAPI population is extremely bimodal in that there are many students that exhibit high success and also many students that are considered "at risk."

\footnotetext{
${ }^{1}$ In this study, the term "Hmong" refers to an Asian ethnic group who identifies themselves as "Hmong," but may be referred to as "Meo" in Thailand and "Miao" in China. "Hmong American" refers to person(s) with Hmong ancestry who are currently residents or citizens of the United States.
} 
Table 1

Asian Population in the United States by Detailed Group Alone or in Combination with Other Races.

\begin{tabular}{|c|c|c|c|c|}
\hline Detailed Group & $\begin{array}{l}\text { Detailed Asian } \\
\text { Group Alone }\end{array}$ & $\begin{array}{r}\% \text { of Total U.S. } \\
\text { Population }\end{array}$ & $\begin{array}{r}\text { Detailed Asian } \\
\text { Group in } \\
\text { Combination with } \\
\text { Others * }\end{array}$ & $\begin{array}{r}\% \text { of Total U.S. } \\
\text { Population }\end{array}$ \\
\hline Total & $14,327,580$ & 4.80 & $17,320,856$ & 5.60 \\
\hline Asian Indian & $2,843,391$ & 0.92 & $3,183,063$ & 1.03 \\
\hline Cambodian & 231,616 & 0.08 & 267,667 & 0.09 \\
\hline Chinese & $3,347,229$ & 1.07 & $4,010,114$ & 1.30 \\
\hline Filipino & $2,555,923$ & 0.83 & $3,416,840$ & 1.10 \\
\hline Hmong & 247,595 & 0.08 & 260,073 & 0.08 \\
\hline Japanese & 763,325 & 0.25 & $1,304,286$ & 0.42 \\
\hline Korean & $1,423,784$ & 0.45 & $1,706,822$ & 0.55 \\
\hline Laotian & 191,200 & 0.06 & 232,130 & 0.07 \\
\hline Pakistani & 363,699 & 0.11 & 409,163 & 0.13 \\
\hline Thai & 166,620 & 0.05 & 237,583 & 0.06 \\
\hline Vietnamese & $1,548,449$ & 0.50 & $1,737,433$ & 0.55 \\
\hline Other Asian & 644,699 & 0.20 & 623,761 & 0.20 \\
\hline
\end{tabular}

Source: U. S. Census Bureau, 2010

Notes: The 2010 Census showed that the US population on April 1, 1010 was 308.7 million. Out of the total US Population, 14.7 million, or $4.8 \%$, were Asian alone. In addition, 2.6 million people, another 0.9 percent, reported Asian in combination with one or more other races.

*The numbers by Detailed Asian Group do not add to the Total Asian Population. This is because the detailed Asian groups are tallies of the number of Asian responses rather than number of Asian respondents. Respondents reporting several Asian groups are counted several times. For example, a respondent reporting "Korean" and "Filipino" would be included in both Korean and Filipino numbers.

As highlighted by Table 1, Southeast Asians are a significantly underrepresented ethnic sub-group, which comprises of people from a variety of Asian ethnic groups from the countries of Vietnam, Laos, and Cambodia (Ngo \& Lee, 2007; Teranishi, 2004). They came to the United States in the late 1970s and 1980s as political war refugees, fleeing their home countries as an act of desperation to escape from poverty, torture, and death from the aftermath of the War on Southeast Asia (also known as the Vietnam War) (Ngo \& Lee, 2007; Teranishi, 2004). The 2000 U.S. Census showed that $49 \%$ of Southeast Asians live in poverty, compared to less than $10 \%$ of Japanese and Chinese Americans (Teranishi, 2004), which indicates that the experiences of this specific population is distinct from other AAPIs that have been in the United States for numerous generations. Additional information regarding the current status of Hmong in the U.S. compared to other ethnic groups can be found in Table 2. 
Table 2

Some Socio-Economic Indicators for Selected Groups in the United States.

\begin{tabular}{lccccrr}
\hline & $\begin{array}{l}\text { Median } \\
\text { Household } \\
\text { Income }\end{array}$ & $\begin{array}{l}\text { Per } \\
\text { Capita } \\
\text { Income }\end{array}$ & $\begin{array}{l}\text { Poverty } \\
\text { Rate }\end{array}$ & $\begin{array}{l}\text { School } \\
\text { Diploma }\end{array}$ & $\begin{array}{l}\text { Bachelor's } \\
\text { Degree }\end{array}$ & $\begin{array}{r}\text { Unemployment } \\
\text { USA Total }\end{array}$ \\
All Asian American & $\$ 65.1 \mathrm{~K}$ & $\$ 27.1 \mathrm{~K}$ & $14 \%$ & $86 \%$ & $31 \%$ & $8 \%$ \\
Hmong & $\$ 28.3 \mathrm{~K}$ & $12 \%$ & $8 \%$ & $50 \%$ & $6 \%$ \\
African American & $\$ 32.1 \mathrm{~K}$ & $\$ 11.0 \mathrm{~K}$ & $38 \%$ & $61 \%$ & $14 \%$ & $11 \%$ \\
Hispanic & $\$ 17.5 \mathrm{~K}$ & $25 \%$ & $81 \%$ & $18 \%$ & $13 \%$ \\
White & $\$ 38.6 \mathrm{~K}$ & $\$ 15.5 \mathrm{~K}$ & $22 \%$ & $61 \%$ & $13 \%$ & $9 \%$ \\
\hline
\end{tabular}

Source: U. S. Census Bureau, 2011

\section{Hmong Americans in the United States}

The Hmong people are a rapidly growing population in the United States, constituting one of the most sizeable Asian ethnic communities in the Upper Midwest and in some regions of the West and the South (Schaefer, 2008). According to the 2010 Census, there are 260,073 Hmong in the United States, with its largest settlements in California $(91,224)$, Minnesota $(66,181)$, Wisconsin $(49,240)$, North Carolina (10,864), and Michigan (5,924) ( "Hmong American Partnership," 2010; Lee \& Green, 2008; Pfeifer, Sullivan, Yang \& Yang, 2012). In fact, according to Asian American Center for Advancing Justice's "A Community of Contrasts Asian Americans in the United States" (2011), Hmong are the $9^{\text {th }}$ largest Asian ethnic group living in the U.S.

Historically, the Hmong people are a stateless ethnic group who has origins in China. Following their persecution in China in the $19^{\text {th }}$ century, a large population of the Hmong people moved to Thailand, Burma, Laos, and Northern Vietnam, where they predominantly lived until 1975 (Tatman, 2004; Yang, 2003). Many Hmong still live in these countries, including China, to date (Yang, 2003). During the 1960s and 1970s, Hmong were recruited by the Royal Lao Government (RLG) to fight against the Communist Pathet Lao and the Northern Vietnamese (Savada, 1994). Under the leadership of Major General Vang Pao, about 30,000 recruited Hmong worked closely with the United States' military and fought in the "Secret War" in an effort to maintain their freedom (Dodson, 2011; Schaefer, 2008, Wausau, 2004; Yang, 2003). During the Secret War, the Hmong in Laos were split into three factions; about a third fought alongside the RLG and received support and training from the U.S., and another third with Communist Pathet Lao. The rest were neutral, but still suffered greatly from the effects of the war which caused displacement, war casualties, and division among the Hmong (Savada, 1994; Yang, 2003).

When the United States withdrew from Vietnam after the fall of Saigon in 1975, the Hmong that supported the Royal Laotian Government experienced severe retaliation and were "targets of genocide" from the Northern Vietnamese and Lao Communists for their partnership with the United States. As a result, there were thousands of deaths and a massive fleeing to Thailand for refuge in refugee camps (Dodson, 2011; McNall, Dunningan \& Mortimer, 1994, Tatman, 2004; Wausau, 2004; Yang, 2003). More specifically, after the final communist takeover of Laos and Vietnam, the Hmong fled to Thailand where the United Nations High Commission for Refugees (UNHCR) assumed responsibility for them until they could officially migrate (Culas \& Michaud, 2004). The primary reasoning behind UNHCR's action of helping 
the Hmong people avoid retaliation or "re-education" by communist Pathet Lao was due to the Hmong's collaboration with pro-American or Royalist forces (Culas \& Michaud, 2004).

From the late 1970s to the mid-1990s, large numbers of Hmong refugees were resettled in the United States, with an estimated admittance of over 100,000 Hmong refugees (Schaefer, 2008; Wausau, 2004; Yang, 2001). For many Hmong, the decision to come to the United States was not necessarily based on economic opportunities, but rather, escaping from life-threatening circumstances including repatriation from camps in Thailand (McNall et al., 1994). In fact, most Hmong did not come to the United States with the intent of seeking a new life, but with the intent of preserving their old life in a new location (Bulk, 1996). In addition to the Hmong's forced dispersion to at least two foreign countries, their post-war experience also included their struggle with maintaining collective memory of their homeland and a Hmong ethnic consciousness (Yang, 2003).

Upon migrating, the United States government enacted a "scattering policy" that attempted to spread out Southeast Asian refugees, which included Hmong refugees, evenly throughout urban and rural areas of the United States to encourage acculturation (Schaefer, 2008; Tatman, 2004). The Hmong had no say in location of migration; instead, voluntary resettlement agencies (volags) selected locations based on benevolence of Catholic churches willing to take part in the resettlement (Bulk, 1996). These policies resulted in the resettlement of Hmong in predominantly poor communities, where they encountered considerable hostility and violence (Schaefer, 2008). Moreover, these policies were not long withstanding, as the Hmong community relocated massively during the mid- to late 1980s to central California in search of economic betterment, reunification with their extended family, as well as cultural ritualists from their traditional Hmong religion (e.g., shaman and ceremony facilitators) (Bulk, 1996; McNall et al., 1994; Schaefer, 2008; Yang, 2003). It is stated that Hmong have obligations to stay close to extended family, more so than other Southeast Asians (Bulk, 1996). This "secondary" migration to central California was also attributed by sponsorship from existing Hmong families in the United States and was based primarily on family, housing, and employment (Yang, 2003; Vang \& Flores, 1999).

The Hmong population continued to shift in the 1990s, where they moved away from the West and toward the Midwest and the South for opportunities for a better life (Yang, 2001). Most notably, St. Paul, Minnesota became the unofficial Hmong American capital of the U.S. with 64,422 residents in 2010 as it offered low-cost housing, educational opportunities, and the existence of a large institutionally complete ethnic enclave of Hmong refugees (Pfeifer et al., 2012; Schaefer, 2008). According to the 2010 U.S. Census Bureau, an estimate of 126,713 or just under $49 \%$ of Hmong Americans live in the Midwest, with strong concentrations in Minnesota and Wisconsin (Pfeifer et al., 2012). In Michigan, the number of Hmong residents has an estimate of 5,924 in 2010, which fell roughly $10 \%$ from 2000 , perhaps due to slow economic growth in this state over a period of time (Pfeifer et al., 2012).

It should be noted that to refer to the Hmong as a historically nomadic people is somewhat of a misconception. Hmong are "nomadic" only for practical reasons related to agricultural/land needs and/or being pushed out by military; in other words, they generally do not move around as a part of their "culture," but more so out of utility (Bulk, 1996). Such is the case in their migration to and within the United States.

Unlike most immigrant groups from Asia, the majority of the Hmong people, along with other Southeast Asians groups, came to the United States as political war refugees, contributing to their unpreparedness for the modern capitalistic society of their new home (Schaefer, 2008). 
For example, Asian immigrants who came to the U.S. prior to 1975 had higher educational and economic backgrounds as well as different immigration experiences (Ngo \& Lee, 2007). The traditional lifestyle of the Hmong in Laos was agrarian, with little or no formal education (Lee, 2001; Lee \& Green, 2008; McNall et al., 1994; Swartz, Lee, \& Mortimer, 2003). It was typical that Laos offered an average of only two years of formal education for men, while women received no education at all (Swartz et al., 2003). Additionally, Hmong society has been historically functioning as patriarchal. In Laos, households were often composed of anywhere between 9 to 14 people, including both nuclear and extended family. Household was under the authority and direction of the male, usually the oldest male ("CDCP," 2008).

Since arriving in the United States in 1975, education has been a priority for many Hmong, as it is believed that education is necessary to confer a higher status in society (Lee \& Green, 2008; McNall et al., 1994). Yet, the 2010 Census indicated that almost half of the Hmong population (40\%) had no formal schooling, compared to about $1.4 \%$ of the total U.S. population. In particular, older Hmong in the United States may not speak English and may even be illiterate in the Hmong language because written Hmong is itself a relatively recent development, emerging in the 1950s (Census Bureau, 2000; Helsel, 1993). As a result and largely due to language barriers, many young Hmong are forced to make adult decisions on behalf of their parents, since the younger ones understand English (Vang \& Flores, 1999).

The Hmong culture places significant value on family and community, which follows a traditional system that values patriarchal ideology, early marriage and childbearing, as well as hierarchy within the elders of the family (Lee, 2001; McNall et al., 1994; Schaefer, 2008; Tatman, 2004). Within the Hmong American community, there is considerable diversity that includes, but is not limited to, clan affiliations (18 Hmong clans in the U.S.), religion, dialect (e.g., Green Hmong, White Hmong), generational differences, and socioeconomic status (Bulk, 1996; Schaefer, 2008). Most Hmong in the United States speak one of two dialects of the MiaoYao language: White Hmong (Hmong Der Dialect) or Green Hmong (Mong Leng dialect) (Duffy, Harmon, Ranard, Thao, \& Yang, 2004). Approximately 60\% of Hmong speak White Hmong and 40\% speak Green Hmong ("CDCP," 2008; Lee, 2007). Furthermore, the majority of Hmong in the United States practice the traditional Hmong religion, which is a form of animism that believes in numerous spirits and incorporates practices of shamanism (Tatman, 2004). Those who have retained their traditional beliefs generally believe that all natural objects and individuals have multiple souls. Many Hmong still believe in animism, ancestor worship, and the use of a shaman to communicate between the spirit and human worlds; in addition, there are also a number of Hmong that practice Christianity as well ("CDCP," 2008).

Despite the thirty-five years of settlement in the United States, the Hmong people remain one of the most impoverished groups that suffer from injustice and stereotyping, although many do live in middle-class lifestyles and are increasingly obtaining higher education (Dodson, 2011). Success in the educational arena, including higher education, is increasingly critical for access to a middle-class lifestyle, which is the kind of lifestyle represented so vividly by the "model minority" fabrication of Asian Americans. Census data shows that Hmong Americans report annual earnings $(\$ 10,949)$ well below the national average $(\$ 27,100)$ (Asian American Center for Advancing Justice, 2011). It should be noted that many Hmong in the United Statesespecially older men-have largely relied on self-employment (e.g., farming or gardening), menial jobs, or welfare programs for income and health services. As younger Hmong have become more educated, families now depend upon the younger generation to enter the workforce in order to support the entire family and ensure in financial survival ("CDCP," 2008). Table 3 
highlights Hmong Americans as having the lowest per capita income when compared to selected AAPI groups in the United States.

Table 3

\begin{tabular}{cccccr}
\multicolumn{2}{r}{ Per capita Income for Select Groups of Asian American and Pacific Islanders in the United States, 2010} \\
\hline \multicolumn{2}{c}{ Above average for U.S. } & At or near average for U.S. & \multicolumn{2}{c}{ Below average for U.S. } \\
\hline Taiwanese & $\$ 38,300$ & Korean & $\$ 26,100$ & Thai & $\$ 21,700$ \\
Asian Indian & $\$ 36,500$ & Filipino & $\$ 25,800$ & Vietnamese & $\$ 21,500$ \\
Malaysian & $\$ 33,300$ & Indonesian & $\$ 25,700$ & Bangladeshi & $\$ 16,800$ \\
Sri Lankan & $\$ 32,500$ & Pakistani & $\$ 24,700$ & Laotian & $\$ 16,600$ \\
Japanese & $\$ 31,800$ & & & Cambodian & $\$ 15,900$ \\
Chinese & $\$ 30,100$ & & & Hmong & $\$ 10,900$ \\
& & & & United States Average & $\$ 27,100$ \\
\hline
\end{tabular}

Source: Asian Pacific American Legal Center and Asian American Justice Center, 2011

Despite these challenges, there are many Hmong Americans that have found success in the United States. Many of these stories began after 1990. For example, the election of 22-yearold Choua Lee-who is the first Hmong, first refugee from Indochina, and first Hmong woman - to the Board of Education for St. Paul Public Schools in 1992 marked not only the beginning of the Hmong's participation in the American political system, but also the beginning of their social and economic development (Yang, 2003). Furthermore, when the Hmong started to disassociate with the term "refugee" and acted on their American citizenship, they began to refer to themselves as Hmong Americans; many began to realize that only in America are they treated like everyone else and have access to education, economic resources, and political power (Yang, 2003). Many Hmong Americans began to engage in more mainstream businesses such as professional services, health care, the high-tech industry, poultry farming, restaurants etc. during this time (Yang, 2003). Education scholars have noted that Southeast Asian American female students are also going to college at increasing rates, suggesting the emerging changes of gender roles (Museus, 2013).

In this study, Hmong represents a small fraction in the cities, schools, and the state. For the school in which this study was conducted, of the 235 students enrolled, 16 were Hmong, one student was American Indian, and the rest were African American. One effort to address the relative isolation felt by the Hmong American students is through a support program offered to teens that identify as Asian American. This program is run by a grassroots organization that works with the students on a weekly basis, offering social and personal support, educational workshops, and a space for student community-building. The ensuing report examines Hmong American student perspectives on socio-cultural, familial, and interpersonal factors affecting their educational aspirations. Exploring the experiences of this AAPI sub-group (Hmong American) is intended to reveal knowledge that otherwise may be disregarded, yet is essential to understanding the academic capital development of students from underrepresented backgrounds.

\section{Literature Review}

\section{Educational Attainment for Hmong American Students}

Research has indicated that the higher education achievement and attainment gap for the AAPI community is evident, yet it has been dismissed by society's perception of AAPIs as a homogenous group that has no academic needs ("CARE," 2011; Lum, 2009; Sue \& Okazaki, 
1990; Wing, 2007). Comprising of diverse cultures, histories, and conditions of life, AAPIs show bimodal patterns of educational achievement, with high- and low-achieving students from lowand high-income households (Pang, 1990; Wing, 2007). Within this bimodal pattern of educational achievement, Southeast Asians students, such as Hmong American students, are at one end of the spectrum, with rates of postsecondary attainment and degree completion far below the national average in comparison to the other AAPI ethnic groups such as students of Chinese, Japanese, Korean, etc. descent ("CARE," 2011; Museus \& Chang, 2009). More specifically, existing evidence shows that Hmong Americans (14\%), over 25, hold baccalaureate degrees at rates lower than the national average (28\%) (Museus, 2013). It is important to recognize that this bimodal pattern of achievement is evident within the Hmong community as well; in Yang's (2003) study, the author pointed out that at one end of the Hmong educational spectrum, students have achieved beyond academic expectations, while at the other, low academic performance, high dropout rates, and high truancy are prevalent concerns. Through the $1980 \mathrm{~s}$ to present, researchers have identified several unique circumstances that explored the educational experiences and challenges of Hmong American students.

Previous studies conducted by researchers such as Yang $(2001,2003)$ and Ngo \& Lee (2007) discussed the importance of providing a historical context on Hmong educational attainment in order to facilitate the understanding of the current trends of Hmong American students in education. Before their arrival to the United States, educational opportunities were extremely limited, thus knowledge was passed down through an oral tradition (Yang, 2003). Many Hmong had no formal education; very few had the opportunity to attend school prior to 1975, and only a limited minority learned basic reading and writing while staying in the refugee camps in Thailand (Yang, 2003). In Laos, the first village school was built in 1939, the first Hmong graduated high school around 1942, the first college graduates were in 1966, and the first doctorates were awarded in 1972 ("CDCP," 2008). Upon their arrival to the United States, the first Hmong American doctorate was awarded in 1982 (Yang, 2001). Thus, many of the Hmong American students today are either 1.5 or $2^{\text {nd }}$ generation in the United States, with many being the first in their family to attend college (i.e., first-generation college students).

Another circumstance to consider when understanding Hmong American student achievement is the group's historical experience with immigration. Research has indicated that structural factors such as immigration patterns have an impact on the bimodal educational attainment for this AAPI group (Wing, 2007). John Ogbu's (1987, 1990, 1991) "voluntary" vs. "involuntary" framework suggests that there are two types of immigrants; "voluntary" immigrants: those that seek opportunities in the United States and come with an educational background and professional skills, and "involuntary" immigrants: those who live in the United States involuntarily as a result of slavery or conquest. The "voluntary" immigrant families value educational attainment as an avenue for upward mobility and success in the United States, whereas the "involuntary" immigrant families may be educationally disadvantaged as they are more focused on adjustment and acculturation in a country that they did not initially intend to reside in (Sue \& Okazaki, 1990; Wing, 2007). However, this framework does not address refugee status (Takaki, 1995), as most Hmong and other Southeast Asians came to the United States as political war refugees. These contrasting immigration patterns inform the educational achievements (or lack thereof) of AAPI students.

Other research shared differing perspectives on Hmong immigration patterns and attitudes about education. Earlier research asserts that despite difficult circumstances, Hmong fit under the category of "immigrant" (i.e., "voluntary"), as they select to immigrate to the United 
States rather than were forced to come to this country (McNall et al., 1994). This research also points to Hmong American families as being highly supportive of academic achievement as part of the acculturation process. Furthermore, McNall et al. (1994) found that parents of Hmong American high school students had high educational aspirations for their families. Similarly, Yang (2001) found that Hmong students in St. Paul have lower dropout rates, higher educational aspirations, and their parents placed great emphasis on obtaining an education. Nonetheless, parents' primary concern with their children in terms of school experience seems to be weighted towards behavior rather than academic performance (Lee, 2007; McNall et al., 1994). Due to the distinctive educational experiences of Hmong Americans, several factors must be considered to gain a thorough perspective, including the importance of acknowledging that the level of Hmong educational attainment varies from communities and geographical location (i.e., state to state).

In addition to McNall et al.'s (1994) assertion of Hmong American families as being highly supportive of their children's academic achievement, other researchers such as Xiong \& Lee (2011), Lee \& Green (2008), and Vang \& Flores (1999) explored parental support further and alluded that Hmong parents often struggle to support their children in the education arena. These studies illuminated that although Hmong parents understood the importance of an education to the success and survival of their children in the United States, many Hmong parents find it challenging to provide academic support due to their own lack of formal education and refugee experience (Lee \& Green, 2008; Vang \& Flores, 1999; Xiong \& Lee, 2011). Furthermore, previous research showed that there is a common belief in the Hmong community that parents need to provide basic support for their children to be successful in education, such as food, shelter, clothes, school supplies, as well as emotional and spiritual support (Lee \& Green, 2008; Xiong \& Lee, 2011). Other studies about Hmong parental support also showed that a majority of the Hmong parents were primarily involved in their child's elementary and middle school education, but were academically restricted beyond their middle school education (Ly, 2005; Xiong \& Lee, 2005). Despite these circumstances, Hmong American students sought other alternative ways to achieve educational support, with many heavily depending on their siblings for such assistance (Lee \& Green, 2008).

The neighborhoods and peers at school can have both a positive or negative impact on the academic achievement and success of Hmong American students as well. The research of McNall et al. (1994) asserts that academic success is dependent on the presence of similar peer groups such as other Asian Americans, who tend to exert a positive and supportive environment for academic achievement. Conversely, Lee (2005a) illuminated that for Hmong American students growing up in narrowly isolated circumstances, without the presence of similar peer groups and/or large Hmong American populations, the negative impact on academic achievement is substantially evident. It is also emphasized that second generation Hmong youth are increasingly alienated from school, as they are less likely to have the mindset that the newcomer generations have in regards to their hopes of success in the U.S. (Lee, 2007). This offers important insight to the study of Hmong American high school students as their educational experiences are not only based on their families' immigration history and background, but are influenced by the circumstances of their environment (e.g. neighborhoods, and peers) as well.

Previous research also identified the impact of cultural differences on Hmong American student achievement and success. Through Ngo \& Lee's (2007) review of literature on Southeast Asian American students, the authors discovered that early research in the 1980s and 1990s revealed a high drop-out rate of Hmong American students from middle and high school, 
focusing on cultural barriers that these students face in their educational attainment to explain such trends. Ngo \& Lee (2007) also discovered that several researchers reported that certain Hmong cultural expectations existed for girls and women-such as caring for their younger siblings, performing household chores, as well as early marriage and early childbearing-which can have a negative impact on their pursuit of education. However, it is important to note that in order for the Hmong to facilitate their acculturation in the United States, the Hmong culture has transformed in response to economic, social, political, and cultural changes, thus these cultural expectations (e.g., the role of Hmong girls and women) are becoming less of a barrier towards educational attainment.

Although most of the earlier research focused on cultural differences in Hmong American students' educational experience, studies post-1990s included the exploration of structural issues that Hmong American students face. Some researchers have found that Hmong American students have been tracked into lower level courses and were held to low expectations by their teachers (Ngo \& Lee, 2007; Thao, 2003). In addition, a study conducted by Lee (2005a) revealed that Hmong high school students' experiences with racism and poverty have resulted in their cynicism about their educational opportunities in the United States. On the contrary, it has also been argued that Hmong American students that use education as key to obtain social mobility and status attainment tend to do well academically, as they use their obstacles and negative life experiences as a motivating factor to get out of poverty (Hutchinson \& McNall, 1994; Lee, 1997; Xiong \& Lee, 2011). As the research suggests, Hmong American students are faced with several unique circumstances - which include cultural and structural issues - that facilitate their educational experience.

Hmong American students may also be disadvantaged in comparison to the other AAPI populations in their access to college knowledge, which has influence on their educational attainment. Early research alludes to the Hmong community as having lacked the cultural capital to succeed in American higher education (Lee, 2007). College knowledge, defined as the information students need to apply to and attend college (Mattern \& Shaw, 2010), may not be common knowledge that Hmong American students possess as most of these students come from families with little to no college experience and attend underserved schools that provide minimal college guidance. The 2011 CARE report found that a large proportion of AAPI-specifically Southeast Asians and Pacific Islanders - arrive on campuses "underprepared for college-level work, often as a result of growing up in poverty, attending low-performing schools, and being the first in their families to attend college" (p. 13). This could be the result of Hmong American students being largely enrolled in public schools in low-income school districts, and also often being overrepresented in English as a Second Language (ESL) and remedial courses (Xiong, 2012). While there may or may not be a culture of valuing education within the Hmong community, these external circumstances limit the opportunities of these students and their higher educational attainment choices.

To further the need for research, the 2011 CARE report found that despite high educational attainment rates for AAPIs, Southeast Asians and Pacific Islanders suffer from high secondary drop-out rates and low rates of college participation. As a result, nearly half of the Southeast Asian and Pacific Islander students who are able to get into two- and four-year colleges never ultimately receive their degrees (Cepeda, 2011). Contrary to the belief that AAPIs are overwhelmingly represented in higher education and do not need academic assistance, these statistics assert that the underrepresented AAPI sub-groups (e.g. Hmong) are in need of academic preparation to not only ensure their higher education attainment, but also their retention in higher 
education as well. For example, amongst underrepresented groups of students in higher education, Hmong Americans closely resemble degree attainment rates similar to that of other ethnically underrepresented communities such as African Americans and Latinos; according to the 2010 American Community Survey, 14.5\% of Hmong Americans age 25 and older have attained a bachelor degree or more, compared to $18 \%$ of African Americans and 13.1\% of Latinos (Lee, 2007; Xiong 2012). Additionally, nearly a third of Hmong adults have less than a high school diploma or equivalent ("CARE," 2011). The critical need of academic preparation for Southeast Asian students like Hmong American students is often undermined by falsely aggregated data, which has negative implications on these students in their access and pursuit of higher education. This plays a large role in promoting and perpetuating the Model Minority Myth (MMM).

\section{Model Minority Myth}

Understanding the socially prescribed label on AAPIs as "Model Minorities" is essential to this research. The implications of this label results in the assumption that the entire AAPI student population has no serious academic problems, that they receive strong support for educational achievement from their parents and ethnic communities, and that they are from well-educated middle-class families (Wing, 2007). However, the laudable successes that are clearly evident also mask huge discrepancies within the AAPI population that is far from monolithic.

The "Model Minority" stereotype perpetuates the assumption that the political structures of American society allow for success and the achievement of the American Dream for all groups; it also acts to racialize AAPIs and renders them as the "Invisible American" even though they are the third largest racial minority group in the United States after Latinos and African Americans (Ngo \& Lee, 2007; Teranishi et al., 2004). Additionally, in the discourse over access and equity in higher education, the common assumption that AAPIs are a successful minority group that even "outwhite the Whites" further exacerbates their identities as the "invisible" or "missing" minority - rendering those AAPIs that are living in poverty and are going without needed social and educational services invisible ("CARE," 2011; Inkelas, 2003; Teranishi et al., 2004; Wing, 2007 ).

Previous researchers have been dispelling the MMM about universal academic success for AAPIs for over two decades (Museus \& Chang, 2009). Such stereotypes often create psychological distress for AAPI students, as those students that do not embody the successful stereotypical image may experience low self-esteem and have low self-confidence (Her, 2014). In the context of higher education attainment, statistics show that of the AAPIs enrolled in higher education, nearly half attend two-year public institutions ("CARE," 2011; Chang, 2008; Lum, 2009; Teranishi et al., 2004). Specifically, the experiences and needs of Hmong American students are often overlooked and unaccounted for. In reality, such thinking is not only mythical, but can also prove to be an additional barrier for Hmong Americans whose educational attainment is closer to that of Latinos and African Americans. For example, according to the 2010 U.S. Census Bureau, the Hmong community had the lowest rates of educational attainment out of all AAPI groups, with $61 \%$ of Hmong having received high school diplomas, and only $14 \%$ having received bachelor's degrees. Moreover, Hmong parents - many who are firstgeneration refugees - are generally uneducated about the American school system and lack the understanding of how to be involved in their children's academic lives. This is in stark contrast 
to the assumptions of all AAPIs attending highly competitive four-year universities and graduate programs nationwide.

Generally, we find it important to situate the discussion around the MMM within the broader context of U.S. society. In other words, the MMM benefits the agenda of the "American Dream" by assuming that an ethnic minority group (e.g., AAPIs) is able to "make it in America" without the use of special assistance (Ngo \& Lee, 2007; Wing, 2007). This is problematic primarily because the effect of the myth is detrimental as it acts to deplete the recognition and need for additional resources for historically underrepresented and often struggling AAPI communities, like the Hmong community, thus having a substantial impact on their educational attainment.

\section{Academic Capital Formation}

ACF is a concept developed to understand academic success beyond degree attainment and professional employment (St. John, Hu, \& Fisher, 2011). As defined by St. John, Hu, and Fisher (2011), ACF is a set of social processes that allows for cross-generational uplift toward educational attainment and career success. The theory of ACF adapts constructs from economic, social, and cultural theories of capital formation to study student educational transitions (St. John et al., 2011). Built upon social processes of networking and trust building from social capital theory, rational analysis of educational costs from human capital theory, and concepts of cultural capital from the cultural theory of social reproduction (St. John et al., 2011), ACF provides a new way of viewing how students from underrepresented backgrounds navigate their pathways into higher education and transition into college life (Lee \& St. John, 2012).

The ACF framework includes six core constructs that study student educational transitions: Easing Concerns about Costs, Supportive Networks in Schools and Communities, Navigation of Systems, Trustworthy Information, College knowledge, and Family Uplift (St. John, 2012). Table 4 highlights the core constructs of ACF. These core constructs of ACF will be utilized to examine Hmong American student experiences as they make decisions regarding their educational transitions and higher education attainment. It is noteworthy to mention that these constructs work independently and in conjunction with one another to maximize the understanding of students' academic capital formation and educational outcome. This study will draw on relevant research related to the educational attainment for Southeast Asian American students (with prime focus on Hmong American students) as well as research on the impact of the MMM. Issues such as socioeconomic status, community involvement, educational environment and quality, language and cultural issues, and awareness of the opportunities afforded by a higher education are explored.

\section{Methodology}

Data for this study was generated from focus group interviews and discussion with students who participated in a support program that provides educational workshops and a space for building community among Hmong American students. The support program is a grassroots organization that works with the students on a weekly basis at their school. We conducted the focus group with seven Hmong American students from the program who attend a singular high school that is one of three "small school academies." The high school population itself reflects a larger proportion of Asian Americans than that of the city, yet the number of AAPI students attending 
is relatively minuscule: AAPIs represent $7 \%$ of the school's enrollment, while $93 \%$ of the remaining population is African American.

Table 4

Social Processes Integral to Academic Capital Formation

Easing Concerns Concern about college costs is an inhibiting force for low-income students, especially when about Costs: parents have no personal knowledge of college. Aid guarantees provide a way to overcome these fears.

Supportive Networks Mentor, teachers, and community leaders can help students and parents overcome fears in Schools and about pursuing an education and paying for it, easing the process of learning about college.

Communities:

Navigation of Navigation through barriers requires the ability to deal with classicism and racism. It builds Systems: knowledge that is transferable across educational transitions and can be conveyed through mentorship and social networks.

Trustworthy Accurate information received from people at critical times emerges as important in the Information: process of overcoming educational barriers.

College Knowledge: A form of cultural capital that includes the capacity to envision one's self and family members as college students, building understanding of the roles of courses and majors in preparation for graduate education and the workforce, and the ability to use human and information resources to discern and pursue appropriate pathways through educational systems.

Family Uplift: $\quad$ A pattern of behavior within family systems and extended networks that supports the acquisition of college knowledge, navigation of education and employment systems, and expansion of educational opportunity across generations.

Source: St. John, 2011

The interview protocol was designed to understand the factors that impact these students' desire, perception, and ability to pursue higher education, particularly through understanding the role that ACF plays in their decision-making. The protocol also considered literature on college access for underrepresented communities, educational experiences of AAPIs, and the MMM.

\section{Qualitative Approach}

Qualitative interviewing was selected because it allowed for a deeper understanding of the phenomena of study (Rubin \& Rubin, 1995). Interviews provided insight into how people interpret and understand complex relationships, and how current behavior may have been influenced by past decisions or incidents. The central goal of these focus group interviews is to understand how the research participants think (Bogdan \& Biklen, 1992). In this case, we are interested in what the participants think about higher education; more specifically, we are interested in how the development of academic capital impacts their desire to pursue or not pursue higher education.

Students were selected by purposeful sampling to generate information-rich cases and allow the researchers to focus in-depth on investigating and understanding a small group of subjects. Purposeful sampling is used by qualitative researchers and allows for the discovery and 
understanding of complex phenomena (Merriam, 1998). Research participants also comprise a "convenience sample" based on their program participation, availability, and accessibility (Merriam, 1998; Patton, 1990).

The design of this study was based on uncovering the ACF of Hmong American students through the interview process. Although focus groups risk the potential of being used inaccurately as a mass interview tool, the primary use of a focus group in this study was to provide a space for us to observe the various perspectives of the research participants as they build on each other's ideas and concepts in response to interview questions (Stage \& Manning, 2003). Our study was a particular attempt to expose contrasting points of view amongst participants coming from a similar demographic. Prior to completion of the focus group, students were encouraged to participate in individual interviews in an effort to further glean information, data, and perspectives about the participants' experiences. One student participated in an individual interview after partaking in the focus group.

\section{Recruitment}

Preceding the focus group, the students experienced an interactive presentation on the themes of our research (e.g. the MMM and relevant data about AAPIs today), which was presented during one of their support program sessions. Recruiting from the support program was utilized because the primary demographic of Hmong American students who attended the high school was also enrolled in this program. This gave us access to the majority of students whom we considered to be ideal candidates for our focus groups and interviews. These students were quasi involved in college readiness, and were considered potential first-generation college students. We worked closely with a supportive adult mentor from the group to coordinate the site visit and presentation as well as to follow-up with students through social media tools. Students were given the opportunity to sign up for our focus group and were promised a small incentive in the form of a store gift card for their voluntary participation.

\section{Data Collection}

The focus group interview session occurred at a mutually agreed upon time and place that was convenient travel distance for the participants. Participants were assured of confidentiality regarding their comments. The focus group lasted 120 minutes, and the individual interview lasted 30 minutes. Transcription was done manually in order to ensure that the richness and detail of the data was maintained (Merriam, 1998).

Merriam (1998) describes interview formats that range from highly structured to openended and conversational. A semi-structured interview format was used in this study; this structure allowed for the exploration of the students' ACF as it relates to their perceptions about higher education. It also facilitated a space where participants could share perspectives in their own words. Research questions were explored at the "saturation point," that is, until no new information was forthcoming (Rubin \& Rubin, 1995).

The following sample questions were posed to study participants:

- Tell us a little about where you grew up and your experience there.

- How close/connected do you feel you are to the Hmong community?

- Who are your role models/mentors and why?

- Can you please describe your high school and your experience there? 
- Can you tell me, how 'well' do you think your high school is preparing you for college?

- What do you plan to do after high school?

- What things have you learned about the college-going process (i.e., requirements, admissions, financial aid, etc.)?

- Do you or your peers see Asian Americans as high achieving college goers?

\section{Data Analysis}

The research questions and previous literature on ACF, Hmong American student educational experience, the MMM, and college access for underrepresented communities guided the analysis of this data. With this study, we seek to expand on current research derived from the literature on college access for underrepresented communities with the goal of developing categories, patterns, and themes that will eventually lead to increased and more accurate interpretations and findings.

Data was transcribed, sorted, reduced, and coded to facilitate analysis (Murphy, 1980). Each individual interview was summarized in written form, including short biographical information on the participants and an initial overview of what played a role in their ACF and decision-making in regards to pursuing higher education. Once the data was coded, it was grouped in "provisional categories" or themes (Lincoln \& Guba, 1985) based on prior literature and our research questions.

The following are the pseudonyms, grade level, and brief biography of the research participants. Each student that participated in this study was a $2^{\text {nd }}$ generation Hmong American, and potentially a $1^{\text {st }}$ generation college student:

Vang, $9^{\text {th }}$ grade

Vang is the second youngest in the family out of four siblings.

Vue, $10^{\text {th }}$ grade

Vue is the youngest of three. Vue has two older sisters who are currently attending college. Vue has an interest in following her sisters' footsteps and is involved in school.

Yang, $10^{\text {th }}$ grade

Yang has one older brother who is currently enrolled at a community college. Yang has moved around in the Midwest a few times and has attended several different schools.

Lee, $11^{\text {th }}$ grade

Lee has two older brothers and is the youngest of three. Lee's older brothers spent some time in college but ultimately dropped out. Lee is very engaged in school activities related to the support program.

Pa, $11^{\text {th }}$ grade

$\mathrm{Pa}$ is the oldest of four siblings, with two younger sisters and one younger brother. $\mathrm{Pa}$ has a part-time job after school. 
Pang, $11^{\text {th }}$ grade

Pang is the second oldest out of four. Pang is very engaged in school activities related to the support program.

Xiong, $11^{\text {th }}$ grade

This student only disclosed her grade level.

\section{Limitations}

There are three limitations that warrant attention to this research study. One possible limitation is the sample size, which only consisted of seven participants. Due to our small sample of students that are also isolated in comparison to students from other largely populated Hmong communities (e.g., California and Minnesota), this study may not be a representative of all Hmong American students.

In addition to the sample size, another limitation is the lack of gender balance within the group of research participants. During recruitment, we found it challenging to bring on male students and were only able to recruit one for the study. The disproportional representation of female participants to male participants can possibly be attributed to the minimal male participation in the support program.

A selection bias constitutes the third limitation of this study. The students self-selected themselves to participate in the support program, which may have influenced their decision to engage and share their perspectives. Furthermore, the experiences and perception of this selfselected group may differ from those who are not involved in the support program.

\section{Findings}

In exploring with students the factors that explain and influence their decision-making about higher education, four particularly salient categories emerged: 1) the impact of their selfperceived marginal status within the community, 2) Hmong cultural influences, 3) the K-12 educational experiences, and 4) a dearth of "college knowledge" resources. These findings lend themselves to interpretation within the ACF framework.

\section{Self-perceived Marginal Status within the Community}

Understanding the environments in which the research participants grew up in is essential to examining their ACF. We observed several common themes from the focus group data that illustrate the challenges faced by being a distinctive minority group residing in an urban community. Students spoke at length about Hmong American struggles living in a high poverty community and the resultant pressure to relocate to nearby suburban areas. For example, Yang commented:

We used to have this really big Hmong population here, but I guess because of the bad environment that we are surrounded by, you know, abandoned houses, and a lot of criminal cases and stuff, I guess everybody just pretty much moved out. 
Other students mentioned that their family's homes and cars were damaged by attempted break-ins on multiple occasions. One student disclosed that their father felt the need to have a firearm in the home and wielded it once to chase off a robbery attempt. Vue described multiple attempted break-ins of their home, even while it was occupied:

I remember it was just me and my sister and my grandma in the house, and then all of a sudden you hear like a big knock, not a knock, a bang on the door. It was so loud; it almost made the house shake. We looked out the window and saw a man trying to break into our house. It wasn't the first time either. It made my dad put up this cage — these bars on the windows.

Several students had normalized these types of incidents. Pa discussed this "normalization" further and how non-residents might experience their neighborhood:

If you heard about violence around you, it's really scary. But I'm used to this kind of thing you know. It's not really that scary for me; I could just walk one mile to school and one mile back, so it's okay. But maybe other outsiders come in you know, they're probably - they be scared to death, but I'm used to it.

Another student agreed, stating, "It's normal for me too. You know, you just always have this feeling like you're being watched. But I'm used to it." These sentiments of experiencing and then normalizing potentially unsafe conditions are integral in understanding the obstacles impacting their ACF. The sentiments underscore the challenge of finding a supportive network within the community to help ensure the success of these students in the face of such obstacles, as highlighted by the ACF framework.

Additionally, students identified a lack of resources, both in terms of time and money, as a major obstacle to their educational aspirations. When asked about Yang's life at home and outside of school, Yang highlighted the relative lack of resources by stating,

We only share one computer and my brother is always using it for his homework and stuff. So I can't really just log onto the computer and try and look up colleges and stuff, like I don't have that much time, because I gotta work, and I'm hardly home because I have school and then in the afternoon I go to work and I don't come back until night.

As implied by this student's statement, it is evident that navigation of systems play a crucial role in facilitating the ACF of the student. This shows the need for a strong sense of social agency in order to accomplish goals in the wake of a number of obstacles related to a lack of resources.

Like many AAPIs, these students also experience being categorized as belonging to a specific ethnic group in which they do not identify with and is a common result of the MMM. That is, several students discussed their experience with being mis-labeled as Chinese Americans, which led many of them to question the roots of their Asian backgrounds. Vue described the following experience:

I think we all faced racism, but when I was little I didn't know what racism was. At first in elementary school everybody wanted to be my friend 'cuz I was different. But then, sometimes walking home with my friend, kids would try to mock us like "ching-chong" 
like that, you know. They would call us Chinese even though we are not. I went home and told my sister about it and she said that was racism.

This situation seemed to be exacerbated by the fact that there were no formal educational opportunities to learn about Hmong American history in their classrooms. Instead, these students gained information about their culture and history almost exclusively from members of the support program and from family members.

Teachers were not particularly knowledgeable about Hmong history. One student commented: "We don't really know [Hmong history] - I barely know anything about Hmong." Lee explained how this has an emotional impact, "I don't know, I felt really depressed, I was kinda down, because in middle school I was like the only Hmong person. And then I asked my teacher, I was like 'is Hmong a race?' and he was like, 'Yes it is.' And that was it." Other students showed their knowledge of Hmong history and leaders, much of which was given to them explicitly by family members, and much of it seemed to leave lingering questions about whom they could look up to as role models. This highlights the need for trustworthy information as noted in the ACF framework. The lack of essential information, in this case related to Hmong identity, plays a role in a student's formation of social and academic capital.

Given these exceptional circumstances, the Hmong American students in this study reveal an upbringing that is both challenging and isolating. Through supportive networks such as their support program, these students seem to have found a space to voice these experiences. This is highlighted in their ability to feel safe enough to communicate these difficult circumstances in the focus group sessions. Moreover, the opportunity provided by the support program to develop a peer support network served to fortify against the isolation many of the students felt while growing up in conditions that are harsher than most.

The students' comments about their status within the local community illustrate their self-perception as a marginal group and one that feels considerable isolation from the larger community. Thus, the students' ability to develop academic capital is hampered by the challenges of navigating their way through an uncertain social terrain that can be unresponsive, condescending, or even hostile; by a need to identify reliable sources from whom they can get trustworthy information; and by the need to create a supportive network of peers and adults.

\section{Hmong Cultural Influence}

The students were asked questions intended to elicit insights about the ways in which their own ethnic community influenced their academic experience. In general, students' responses indicated that that they did not have enough positive examples and role models to emulate in their community. Pa's perceived lack of positive role models was used as a source of motivation.

I kind of look up to my dad because, you know, it happened years ago, this one night he came home drunk... and so he was talking to me and he looked me in the eyes and told me, he said $[\mathrm{Pa}]$, he said "don't do what I do"... he told me to get a good education and he told me to go to college and be a doctor and all that. And so I kind of look up to my dad because of that.

This student interprets this experience to mean that this student should do the opposite of what the father does, while at the same time, following the father's advice. This student also 
acknowledges a lack of positive role models with regards to educational attainment within the community.

Three students spoke about how their Hmong community was fractured by a lack of trust for one another. For example, Lee sheds important insight on the possible historical contexts leading to this circumstance in the following way:

Part of that whole trust thing is where we came from. Because our whole country was taken over, and then we had nobody to lean on and then more and more Hmong people were getting killed and as we went to Thailand and Laos we have even more trust issues because we didn't get along with the Vietnamese people during that time, so we had to go to America and most of the families had to start on their own.

Not only does this statement reflect the fractured trust being discussed above, but it also makes evident the lack of historical facts known by the students (e.g. that the Hmong do not have a "country" and that Communist Pathet Lao, along with the Northern Vietnamese, took over areas of Laos-not just the Vietnamese on their own), which may have exacerbated this feeling. Furthermore, Lee spoke vividly about the difficulties that the Hmong people experience in America:

I know that other people started with nothing in this country. It's hard; but then for us, it's hard because we have no family members in America, so we had to start off with basically one family who had no one to lean on so it's hard to trust whatever. So I think trust is a big issue in our community in my opinion.

These statements further accentuate the lack of supportive networks and trustworthy information that these students have access to in order to be successful educationally.

As a way of dealing with these disadvantages, many Hmong families have had to make adjustments to their way of living, one of which is around language and culture as referenced in the following statement made by Yang:

Parents have their own way of raising children, some choose not to teach their children how to speak Hmong at all because they think it will ruin their school, right? Because for me, balancing both English and Hmong was really hard; but to my parents, they believe we should keep our native language, our native tongue. I had problems talking to my teachers, I would talk Hmong to them and they would go like "what'd you say sweetie? What did you say?" It was really hard and that's why every year I had bilingual [education classes]...Later I didn't understand why I had bilingual because I don't think I need it anymore... but they keep giving me bilingual.

This statement highlights the intersection of both the familial pressures of the Hmong community as immigrants as well as the way in which the educational system perpetuates the status of these students as immigrants by repeatedly enrolling them in ESL courses (referred to as "bilingual"), despite possessing a visibly adequate level of English mastery.

In addition to these linguistic challenges, students expressed having to play a substantial role in raising their younger siblings and motivating them to be as successful, if not more so, than themselves. Most students in this study came from large and often disjointed families, 
where the children subsumed parenting roles as well. Circumstances such as these undoubtedly impact the potential for the influence of positive family uplift (i.e., family habitual patterns of behavior that encourage educational aspiration). Therefore, these additional responsibilities impose further challenges to the ACF in the students.

Historically, Hmong culture does not have a tradition of college-going and there are few Hmong Americans with a college degree who could serve as role models for younger generations. Furthermore, language isolation, along with a close-knit family cultural tradition and few non-familial sources of trustworthy information, serve to limit broader social interactions that might encourage college going. Moreover, the dominant American culture is generally so uninformed about Hmong as to be unable to distinguish them from other Asian American populations. These issues, in combination, pose obstacles to students' ACF by limiting access to trustworthy information and opportunities for family uplift in terms of habitual patterns of behavior that promote higher educational attainment.

\section{K-12 Educational Experiences}

Examining the Hmong American students' K-12 pathways inform their educational experiences in relation to ACF. In the interviews, the students discuss how stereotypical images of Hmong identity impacted their experiences and expectations. Pa expressed this clearly:

People would just mess with you just 'cause you're different. They will probably look down on you or maybe look up to you or think you are good at math just because you're Asian. So when they think that you're good at math and reading, they always come to you or ask you for help because they think you know everything, but I don't really know anything.

The stereotypical expectations of Asian Americans as "Model Minorities" have an adverse impact on the students' concept of their own academic ability; because this student does not feel that $\mathrm{s} / \mathrm{he}$ is living up to that stereotypical expectation, this student blames his/her lack of academic ability specifically on oneself, making invisible the larger structures such as the school system and community that may have contributed to this student's feeling of academic underpreparedness.

The students' local school system is plagued by a variety of issues all too typical of urban settings that negatively impact student development and success, thus contributing to the students' self-perceptions of their academic competence and preparation for college. The students vocalized the school system's lack of resources by comparing their educational experiences to that of acquaintances who attend well-resourced schools. Vue, in particular, emphasized:

Sometimes I look at my school and I feel like, oh man, the suburban schools are doing much better because they have more programs...our schools lack funding and we don't have enough money for all these things...the curriculum here is falling behind and is slower than schools in suburban areas.

Yang agreed and made a comparison to another high school in a nearby state. Yang asserted, "When I lived in [nearby state], we're already close to pre-calculus. But then when [my family] 
moved back here, we're still in algebra. I was like, what? So that kind of messed me up." The group unanimously felt the lack of resources has contributed to the students' feeling of being under-prepared for college, which essentially informs their ACF-particularly so for acquiring college knowledge as they begin to think about their postsecondary options.

Some of the students indicated that there is a "lack of hope" within their educational system. For example, Yang mentioned:

We go to a school where there's a lack of hope...the system is trying, but I feel like they're not trying hard enough. They can't reach the students. They don't try hard enough to actually understand how we learn. I feel like we students need more help; there's just not enough help here. The teachers are trying, okay, but they don't try hard enough to understand how we learn.

Xiong mentioned that the teachers have a tendency to add to this "lack of hope" culture, stating: "Some teachers, they just give you the work and when you ask questions like, 'um, how do I do this?' They say, 'just do it'...the teachers are not guiding you, there's no guidance...there's a lot of miscommunication going on." According to these participants, the culture of "lack of hope" within the schools exists on multiple levels: the students, the teachers, and the school administrators.

This is further emphasized by the students' concerns over issues of trust between the students and the school's leadership (e.g., staff members, administrators). Lee expresses this clearly, "I don't feel comfortable approaching the counselor because we don't have a close relationship...there's this thick wall that they can't break through." Xiong further affirms this issue of trust, "I can ask my teachers about college but I wouldn't really prefer to ask them because I don't really want to get that close to them." The lack of trust expressed by the students has a substantial impact on their engagement in school and their perception of educational attainment; the inability to trust school administrators contributes further to this feeling of hopelessness, as the students do not consider school administrators as resources for guidance. ACF's core construct of the need for trustworthy information is again reaffirmed, as it is an apparent ongoing concern among the students.

In contrast, despite such feelings of hopelessness, Vue argued: "I feel like there are a lot of things in our schools that need to be worked on, but I don't feel like it's hopeless." Thus, although several students expressed a "lack of hope" culture in the community at-large, it is important to note that this is not a universal sentiment. Feelings of hope, such as expressed by this particular student, are critical to enabling students to develop agency to navigate the system - which is an important skill deemed essential to form one's academic capital.

Even though student comments reflect certain despair about the educational system, their remarks about teachers were generally praiseworthy. For example, Lee commented:

The schools here are not the best, but they may have the best teachers and the best staff members. They're very warm and supportive; even though people say other school districts are better, I still prefer the schools here. 
Xiong added similar comments:

The teachers are very compassionate. They expect a lot of great things out of me and tell me to come to school every day and to do my best and get my grades and go to college.

Vue compared their teachers to those at other schools:

I think every school has one of those teachers who don't know how to teach correctly...but I feel like the staff here cares about us, you know. We have their numbers; I have my principal's number, I have my teacher's number; I can call or text her. My cousins go to a different school and they don't have the teacher's number. I think it's kinda cool that we have our teacher's number and can call about schoolwork or whatever; it might sound kind of weird, but it shows how much our teachers are willing to help us and how much they care for us.

Student comments about the school environment reflect considerable ambivalence. On the one hand, teachers are caring, supportive and encouraging, but not necessarily demanding of students. In addition, school personnel work in a system that lacks adequate resources to deliver on the promise of education. Thus, students can be cautious about seeking allies among teachers and counselors.

Similarly, in discussing college preparation, the students expressed concern about the extent to which the high school had been preparing them for college attainment. Pang expressed it this way: "High school is kinda preparing me for college, but at the same time, over all the years that I've been there, I don't think I really learned anything." Pa added, "I don't remember any teachers teaching about college...the counselors aren't really dependable; they taught us a little about college, but not really." The lack of focus on college preparation impacts students with respect to their development of college knowledge, which has an influence on their decision to pursue higher education.

One particular student shifted the lack of college preparation from the school level to the individual. Vang stated:

I feel like I am prepared for college, but then, not that much because I feel like it's my fault too that I'm lacking, that I'm not doing well in school so it's not really the teacher's fault. But at the same time it is the teacher's fault because they sometimes love the students too much and make it too easy for us.

This shift from the "blaming" of the school to "blaming" of the self is noteworthy, as it may suggest the impact of the "Model Minority" stereotype on the perception of one's own academic ability and college preparation. In this specific case, it's possible that the "Model Minority" stereotype suggests that one's own college preparation is innate - and therefore, that it is one's own fault if he or she is not academically prepared.

Vue also shared similar views on the school's ability to prepare students for college: "I do feel they are preparing us for college, but I feel like the only thing lacking...is not enough classes; we have basic classes like English, math and science, but what about art?" 
Pa added:

[The school] tries its best, they try very hard to get us ready for college; like I remember with the ACT; they tried to help us as much as possible to get a high score and get us on to college...with tutors and all these programs to help us. So I feel like it's not a matter of ready or not, it's a matter of how you take it.

The students readily acknowledged that there was a problem with respect to school achievement and college aspiration among Hmong American students. They attributed the problem to a variety of issues that impact student school performance, including family traditions that did not encourage educational attainment, economic pressure to work and earn money to help with family expenses, attitudes towards schooling, and conflicting goals for one's life. The students offered a number of suggestions for dealing with the problem, including more encouragement to succeed in school, more opportunities to learn about college options and resources, and more exposure to positive role models who made it to college and succeeded.

Factors such as the school's environment, the impact of Asian American stereotypes, access to educational resources, and information on college preparation are essential to the development of the students' ACF; ultimately such factors influence their postsecondary options.

\section{A Dearth of "College Knowledge" Resources}

The decision to pursue higher education is influenced by a variety of factors. One such factor is the influence of family from whom the majority of the students indicated they learned about college. Vue stated, "I talk to one of my two sisters who attend college...they have experience so they could answer questions for me." Lee somewhat agreed, but with hesitation: "Sometimes I go to my two oldest brothers because they been to college, but they never really finished due to some personal reasons." Despite learning about higher education through familial connections, Lee's comment exposes the problem of college completion within the Hmong community; a challenge for students like Lee is to find role models who have actually completed college and who can inform them about the college experience.

Yang indicated that family members influenced Yang's desire to attend college, but negatively: "I remember my mother and I were going to check-up at the hospital downtown and my mom was like, 'your brother uses this street to go to school every day in college, and it's down there'...I started to not want to go to college because of family issues." Considering that the Hmong community is a close-knit group, family members can have a positive or negative influence on one's decision to pursue higher education.

The students also indicated that the parents have a positive impact on their desire to pursue higher education, which illustrates the ACF's concept of family uplift. Pa spoke specifically of this:

Well um to my parents, education is like getting good grades and living a successful life...earning money for the family and for others. They express their support in a way of taking you to school everyday and they always tell me to do my homework and get my work done...they actually take me to school but it actually self-pressures me 'cause it pushes me to get things done. 
Despite the parents' inability to support them academically, the students indicate that their parents provide support through other means. Their desire to not let their parents down motivates them to do well academically, even though there was a lack of resources in their schools.

Additionally, while the parents do encourage obtaining higher education, the concern about costs has always been a strong influence on the students' perception of their ability to actually attend college. The students unanimously agreed that college costs were an important deciding factor about whether or not they would attend college after high school. Vue speaks of this concern vividly,

Money is an issue because, you know, most of us come from families where our parents never finished high school. They don't know English, they don't understand English. My parents don't have a college education and they don't have the best jobs either so we don't have enough money to go to college. My sister didn't go to college right after high school because at that time, we were struggling with money and she didn't want to put pressure on my parents' shoulders. My parents were disappointed that she didn't go to college but they didn't really understand the reason why she decided not to go to college. My sister didn't want to put more debt in my parents' hands.

The students identify their family's socioeconomic position as well as the cost of attending college as major concerns in regards to their decision to pursue higher education.

Yang expressed a similar concern about financial support for higher education within the Hmong community. Yang commented, "I love my parents a lot and I don't want to spend time in college when I could just work and get that money, like quick money, to just come home and help them out with bills and stuff." Yang illuminates a concern not only about money, but also concerns about careers - a sentiment that is shared by the group collectively. Due to their family's socioeconomic positions, many of the students examine the cost-benefit analysis of their educational choices, prioritizing making money to contribute to the family's economic stability instead of burdening them with extra tuition costs. It should be noted that the students in our study may have limited perceptions about the cost of college, as there are several Hmong American students enrolled in prestigious higher education institutions to date.

Furthermore, yet another factor that has an influence on Hmong American students' higher education attainment are attitudes within the Hmong community itself. The students unanimously indicated that their immediate Hmong community lacks a college-going culture. Yang asserted, "Half of the people I know either got married or are working right now because I don't think college is the first thing on their mind right now." Lee expressed the same concern, "I don't see a lot of Hmong college students. I don't know a lot of that goes to college." Pa agreed, commenting: "I really don't see any Hmong people going to college...to them, college is an option." As mentioned by the interviewees, college is viewed as a secondary option; these particular Hmong American students' primary concerns revolve around making money as soon as possible in order to support their family. This lack of a college-going culture in the Hmong community limits the degree to which family uplift and access to college knowledge can contribute to the students' ACF. These Hmong American students have few role models that successfully completed college, which adversely impacts their perception of college as a realistic option. 
In the interview, students were also asked about their decision to pursue higher education after high school, and a large majority replied with hesitance about pursuing a higher education degree. Lee vocalized this hesitancy,

I feel as if our whole life, we set that goal of going to "college" but then, what about college? I take so much into consideration that, you know, there's money wise, there is no guarantee for a job afterwards... we are not even sure ourselves of what to do; and so, I feel like college is nothing but an empty word to me, because I feel like I don't even know what to do, like what am I even going to do when I get there.

The majority of the students also assert that they do not fully understand the purpose of pursuing higher education. Pa reiterated this lack of purpose clearly, "Twelve years of school is kinda long time. Honestly, school is boring. I probably want to find a good paying job first and then work myself up." These sentiments elucidate the importance of trustworthy information in the ACF of the students; because they do not have immediate trustworthy relationships with schoolteachers and administrators, the necessary college knowledge to gain access to higher education is not acquired. Additionally, given their commitment to their family and to the Hmong community as first-generation students, they feel an obligation to support their family immediately after high school, rather than going to college to continue their education. This further reveals the impact that family habitual patterns, easing concerns about costs, and concerns about careers have on Hmong American students' access to higher education.

As one student mentioned in the interview, going to college is "not as simple as it sounds," considering that there is a multitude of factors that impact the decisions Hmong American students have to make regarding their postsecondary options. Factors such as family obligations, college costs, and the culture of the Hmong community greatly influence ACF, and ultimately affect students' decision to pursue higher education.

\section{Discussion}

The findings of this study support the need for research regarding the educational aspirations among underrepresented Asian American and Pacific Islander student populations. Specifically, this research provides support for previous assertions that there is a bimodal pattern of achievement amongst the AAPI community, and that underrepresented AAPI students (e.g., Hmong and other Southeast Asian students) have experiences similar to those of other underserved communities of color in the United States ("CARE," 2011; Lew et al., 2005; Museus \& Chang, 2009; Wing, 2007; Yang, 2003). The findings also reinforce the notion that the MMM can be damaging to the AAPI community with regards to Southeast Asian student achievement and higher education access ("CARE," 2011; Teranishi et al., 2004; Wing, 2007). Moreover, this study affirms McNall et al. (1994)'s findings that Hmong American families support the academic achievement of their students; however, this study provides further affirmation for previous literature that emphasized parental support in the form of non-academic contributions, as the Hmong parents' knowledge of the American education system is very limited (Lee \& Green, 2008; Vang \& Flores, 1999; Xiong \& Lee, 2011).

Considering that the students' lack of academic preparedness is perpetuated by circumstances of growing up in poverty, attending low-performing schools, and potentially being the first in their family to attend college, our study shows that it is important to be aware of these 
educational barriers and its effects on the students' pursuit of higher education. This study further affirms recent research that suggests the need for increased academic resources for this particular AAPI sub-group ("CARE," 2011). The experiences of these students, in the context of their neighborhood and school environment, serve as a detriment to their ACF (Lee, 2005a; Lee, 2007; St. John et al., 2011). Nonetheless, this study cannot be generalized to represent all of the Hmong American student population, as the experiences of Hmong Americans are vast and differs across the states and transnationally as well.

Ultimately, this study challenges the MMM, which suggests that AAPI students have no serious academic problems, receive strong support for educational achievement from their parents and ethnic communities, and are from well-educated middle class families (Wing, 2007). In reference to our research question of how these students experience the MMM, our findings show that participants decried the stereotype, as it does not reflect their stories and struggles. Through revealing the obstacles faced by the research participants such as growing up in a Hmong refugee family, navigating through an under-resourced educational system, as well as receiving minimal academic preparation and guidance, this study illuminates the harmful implications of such a stereotype towards the academic success and higher education attainment for Hmong American students.

This study also found that environmental factors were of high importance to the students' academic outcomes and postsecondary educational trajectory. In particular, we found that environments that perpetuate increased isolation and disconnectedness had a negative impact on the ACF of Hmong American students. However, it is important to note that the students' development of ACF as it relates to their environment is subjective and cannot be generalized to represent all Hmong American students' educational experiences; in other words, in spite of the students coming from similar demographics, each student has his/her own approach to cope with navigating such barriers.

As delineated from the interviews in our study, the pursuit of higher education after high school is not as forthright as it seems, considering that there is a multitude of factors that can act as hindrances to one's higher education attainment. Through the core constructs that form the framework of ACF, we have identified the relevance of this theory in understanding the academic, social, and economical factors that influence students' educational pursuit within the Hmong community. Moreover, by situating our discussion around the ACF of these students within the context of the historical underpinnings of both the Hmong American experience and its comparison to the implications of the MMM, we see a community experiencing many of the same disparities that other underrepresented ethnic minorities face.

Although this study focused primarily on Hmong American high school student experiences, there needs to be further research to explore and understand the experiences as well as educational needs of all of the pan-ethnic AAPI community. In order to prevent the cycle of reactionary policy making geared towards addressing flaws in the education system, there needs to be increased consideration of all student groups, including but not limited to, AAPI students that do not fit into the problematic schema of the MMM. The way AAPI students form ACF is an area for further research, as it may lead to increased answers as to how to help students move towards college access and completion in an era that is so highly focused on such. 


\section{Recommendations}

While the ACF of these Hmong American students inform their decision of pursuing higher education, their actual ability to attain higher education may be adversely affected by state and federal policies that lack attention to this particular group, thus perpetuating systemic educational inequality. In order to mitigate such structural inequalities and address the misrepresentation of the pan-ethnic Asian American and Pacific Islander community in higher education, several recommendations are proposed to ensure visibility and effective discourse. Based on the lessons learned from pre-existing research, as well as from the research participants of this study, we recommend the following:

1) A disaggregation of data as it pertains to the Asian American and Pacific Islander group in education is critical to determine further the needs of various underrepresented ethnic subgroups. Recent efforts have worked to disaggregate the data of the AAPI community in attempts to acknowledge the vast generational and cultural differences. However, in order to make higher education more diverse and equitable, it is crucial to disaggregate the data in such a way that academic needs and resources can be individually tailored to specific underrepresented AAPI ethnic sub-groups. When this information is provided, AAPI groups may be better suited to address their own specific needs, as did the grassroots organization has in the example of this research.

2) Further research needs to be developed to understand the implications of environmental and community factors on the access of higher education for the larger Southeast Asian student population. Recent research on the educational experiences of Southeast Asian students is very limited. Considering that projected data suggests the population of AAPIs to increase to 40 million persons by 2050 ("CARE," 2011), it is crucial to develop critical framework and research agendas that address the changing needs of the growing heterogeneous demographics.

3) Resources must be created to support the academic issues and challenges of underrepresented AAPI students. Due to inaccurate assumptions such as the MMM which plagues the access and retention efforts of the AAPI community, the academic needs of underrepresented AAPI students tend to be overlooked. Resources in the form of college access intervention programs for underrepresented AAPI students are essential to ensure equity and access to higher education for these students.

4) And lastly, it is critical for AAPIs to be included in the discourse of higher education access and equity to ensure diversity in higher education. Currently, the discourse on diversity initiatives tends to be predominantly focused on the issues of African Americans and Latinos. In the context of an increasingly globalized society, America's concept of diversity needs to be inclusive of all communities in the college completion agenda.

These recommendations support strategies geared towards improving the higher education access agenda for all students. 


\section{References}

Asian American Center for Advancing Justice (2011). A community of contrasts: Asian Americans in the United State: 2011. Retrieved from: http://napca.org/wpcontent/uploads/2012/11/AAJC-Community-of-Contrast.pdf

Bogdan, R., \& Biklen, S. (1992). Qualitative research for education: An introduction to theory and methods. Boston: Allyn \& Bacon.

Bulk, J. (1996). Hmong on the move: Understanding secondary migration. Ethnic Studies Review: The Journal of the National Association for Ethnic Studies, 19(1), 7-28.

Centers for Disease Control and Prevention (“CDCP”) (2008). Promoting cultural sensitivity: A practical guide for tuberculosis programs that provide services to Hmong persons from Laos. Atlanta, GA: U.S. Department of Health and Human Services.

U. S. Census Bureau (2000). Retrieved from http://www.census.gov/main/www/cen2000.html

U. S. Census Bureau (2010). Race main - people and households - U.S. Census Bureau. Retrieved from http://www.census.gov/population/race/

Cepeda, E. (2011). The needs of diverse Asian-American students often overlooked. Contra Costa Times, pp. A-12.

Chang, M. J. (2008). Asian evasion: A recipe for flawed resolutions. Diverse Issues in Higher Education, 25(7), 26.

Culas, C., \& Michaud, J. (2004). A contribution to the study of Hmong (Miao) migration. In N. Tapp, J. Michaud, C. Culas, \& G. Lee (Eds.), Hmong/Miao in Asia (pp. 61-96). Chiang Mai, Thailand: Silkworm Books.

Dodson, A. (2011). Hmong in America: The experience. Diverse Issues in Higher Education, $28(7), 6$.

Duffy, J., Harmon, R., Ranard, D. A., Thao, B., \& Yang, K. (2004). The Hmong: An introduction to their history and culture. Washington, DC: Center for Applied Linguistics, Cultural Orientation Resource Center.

Helsel, D. (1993). "Here there is much more and much less:" Hmong-American families, culture and childbearing in the "land of the giants." Unpublished Doctoral dissertation, University of California, San Francisco.

Her, C. S. (2014). Ready or not: The academic college readiness of Southeast Asian Americans. Multicultural Perspectives, 16(1), 35-42.

Hmong American Partnership (2010). 2010 Census Hmong populations by state. Retrieved from http://www.hmong.org

Hutchinson, R., \& McNall, M. (1994). Early marriage in a Hmong cohort. Journal of Marriage and the Family, 56, 579-590.

Inkelas, K. K. (2003). Diversity's missing minority: Asian Pacific American undergraduates' attitudes toward affirmative action. The Journal of Higher Education, 74(6), 601-639.

Lee, J. K., \& Green, K. (2008). Hmong parental involvement and support: A comparison between families of high and low achieving high school seniors. Hmong Studies Journal, 9, 1-27.

Lee, M., \& St. John, E. P. (2012). Academic capital formation among Hmong students. In Winkle-Wagner, R., Bowman, P. J., \& St. John, E. P. (Eds.), Expanding postsecondary opportunity for underrepresented students: Theory and practice of academic capital formation (Vol. 26 Readings on Equal Education). New York, NY : AMS Press.

Lee, S. J. (1997). The road to college: Hmong American women's pursuit of higher education. 
Harvard Educational Review, 67(4), 803-827.

Lee, S. J. (2001). More than "model minorities" or "delinquents": A look at Hmong American high school students. Harvard Educational Review, 71(3), 505-528.

Lee, S. J. (2005a). Learning about race, learning about "American": Hmong American high school students. In L. Weis, \& M. Fine (Eds.), Beyond silenced voices: Class, race, and gender in United States schools (pp. 133-145). Albany, NY: State University of New York Press.

Lee, S. J. (2005b). Up against whiteness: Race, schools, and immigrant students. New York: Teachers College Press

Lee, S. J. (2007). The truth and myth of the model minority: The case of Hmong Americans. In S. Paik \& H. J. Walberg (Eds.), Narrowing the achievement gap strategies for educating Latino, Black, and Asian students (pp. 171-184). New York, NY: Springer Science.

Lew, J., Chang, J., \& Wang, W. (2005). The overlooked minority: Asian pacific American students at community colleges. Community College Review, 33(2), 64-84.

Lincoln, Y. S. \& Guba, E. G. (1985). Naturalistic inquiry. Thousand Oaks, CA: Sage Publications.

Lum, L. (2009). A deceiving label? There's growing debate among educators on whether the umbrella Asian Pacific Islander label conceals disparities among Asian American students or provides political power in numbers. Diverse Issues in Higher Education, 26(9), 58-59.

Ly, M. (2005). How Hmong adolescents experience parental involvement. $\mathrm{PhD}$ Dissertation, Capella University.

Mattern, K. D., \& Shaw, E. J. (2010). A look beyond cognitive predictors of academic success: Understanding the relationship between academic self-beliefs and outcomes. Journal of College Student Development, 51(6), 665-678.

McNall, M., Dunningan, T., \& Mortimer, J. T. (1994). The educational achievement of the St. Paul Hmong. Anthropology \& Education Quarterly, 25(1), 44-65.

Merriam, S. (1998). Qualitative research and case study applications in education. San Francisco, CA: Jossey-Bass.

Murphy, J. (1980). Getting the facts: A fieldwork guide for evaluators and policy analysis. Santa Monica, CA: Goodyear Publishing Company, Inc.

Museus, S. D. (2013). Unpacking the complex and multifaceted nature of parental influences on Southeast Asian American college students' educational trajectories. The Journal of Higher Education, 84(5), 708-738.

Museus, S. D., \& Chang, M. J. (2009). Rising to the challenge of conducting research on Asian Americans in higher education. New Directions for Institutional Research, Summer, 95105. doi: 10.1002/ir.299

National Commission on Asian American and Pacific Islander Research in Education ("CARE") (2011). The relevance of Asian Americans \& Pacific Islanders in the college completion agenda. New York, NY: New York University. Retrieved from www.apiasf.org/carereport

Ngo, B., \& Lee, S. J. (2007). Complicating the image of model minority success: A review of Southeast Asian American education. Review of Educational Research, 77(4), 415.

Ogbu, J. U. (1987). Variability in minority school performance: A problem in search of an explanation. Anthropology \& Education Quarterly, 18(4), 312-334.

Ogbu, J. U. (1990). Minority education in comparative perspective. Journal of Negro Education, $59(1), 45-57$. 
Ogbu, J. U. (1991). Cultural models and educational strategies of non-dominant peoples. New York, NY: City College Workshop Center.

Pang, V. O. (1990). Asian Pacific American studies: A diverse and complex population. In J. A. Banks, \& C. A. McGee Banks (Eds.), Handbook of research on multicultural education (pp. 412-424). New York, NY: Macmillan.

Patton, M. (1990). Qualitative evaluations methods. $\left(2^{\text {nd }}\right.$ ed.) Thousand Oaks, CA: Sage Publications.

Pfeifer, M. E., Sullivan, J., Yang K., \& Yang, W. (2012). Hmong population and demographic trends in the 2010 Census and 2010 American Community Survey. Hmong Studies Journal 13(2), 1-31.

Rubin, H., \& Rubin, I. (1995). Qualitative interviewing: The art of hearing data. San Diego, CA: Sage Publications.

Savada, A. (1994). Laos: a country study. Retrieved from: http://www.mongabay.com/reference/ country_studies/laos/HISTORY.html

Schaefer, R. T. (2008). Encyclopedia of Race, Ethnicity, and Society Hmong Americans. Thousand Oaks, CA: Sage Publications.

St. John, E. P., Hu, S., \& Fisher, A. S. (2011). Breaking through the access barrier: How academic capital formation can improve policy in higher education. New York, NY: Routledge.

St. John, E. P. (2012). Academic capital formation: An emergent theory. In R. Winkle-Wagner, E. P. St. John \& P. Bowman (Eds.), Expanding postsecondary opportunity for underrepresented students: Theory and practice of academic capital formation. (Readings on equal education, Vol. 26, pp. 3-28). New York, NY: AMS Press, Inc.

Stage, F. K., \& Manning, K. (Eds). (2003). Research in the college context: Approaches and methods. New York, NY: Brunner-Routledge.

Sue, S., \& Okazaki, S. (1990). Asian American educational achievements: A phenomenon in search of an explanation. In D. T. Nakanishi, \& T. Y. Nishida (Eds.), The Asian American educational experience: A source book for teachers and students (pp. 133-145). New York, NY: Routledge.

Swartz, T., Lee J. C., \& Mortimer, J. T. (2003). Achievements of first-generation Hmong youth: Findings from the youth development study. CURA Reporter, 15-21.

Takaki, R. (1995). From exiles to immigrants: The refugees from Southeast Asia. New York, NY: Chelsea House.

Tatman, A. W. (2004). Hmong history, culture, and acculturation: Implications for counseling the Hmong. Journal of Multicultural Counseling and Development, 32(4), 222-233.

Teranishi, R. (2004). Yellow and "brown": Emerging Asian American immigrant populations and residential segregation. Equity and Excellence in Education, 37(3), 255-263.

Teranishi, R. T., Ceja, M., Antonio, A. L., Walter, A.R., \& McDonough, P. (2004). The collegechoice process for Asian Pacific Americans: Ethnicity and socioeconomic class in context. Review of Higher Education, 27(4), 527-551.

Thao, Y. (2003). Empowering Mong students: Home and school factors. The Urban Review, $35(1), 25-42$.

Vang, T., \& Flores, J. (1999). The Hmong Americans: Identity, conflict, and opportunity. Multicultural Perspectives 1(4), 9-14.

Wausau, W. (2004, August 29). Hmong history. Wausau Daily Herald. 
Wing, J. Y. (2007). Beyond black and white: The model minority myth and the invisibility of Asian American students. The Urban Review, 39(4), 455-487.

Xiong, S., \& Lee, S. E. (2011). Hmong students in higher education and academic support programs. Hmong Studies Journal, 12, 1-20

Xiong, Y. (2012). Hmong Americans' educational attainment: recent changes and remaining challenges. Hmong Studies Journal. 13(2), 1-18.

Xiong, Z. B. \& Lee, J. K. (2005). Hmong early childhood education needs assessment. Minneapolis, MN: University of Minnesota.

Yang, K. (2001). Research note: The Hmong in America: Twenty-five years after the U.S. secret war in Laos. Journal of Asian American Studies, 4(2), 165-174.

Yang, K. (2003). Hmong diaspora of the post-war period. Asian and Pacific Migration Journal, 12(3), 271-300.

\section{About the Authors}

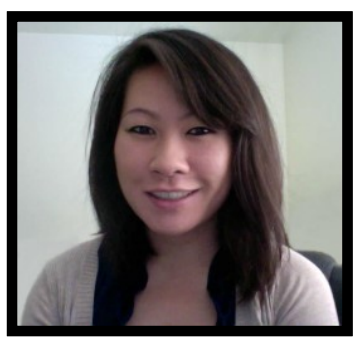

Anna Chiang received her M.A. in Higher Education at the University of Michigan and her B.A. in Ethnic Studies at the University of California, Berkeley. Her academic interest in higher education access and outcome for underrepresented student populations is shown through her years of work in various educational settings, including K-12 and college. Currently, she is an Academic Advisor at Alliant International University, where she works with graduate students on their academic program planning. She also facilitates on-campus diversity initiatives to ensure positive student learning experiences and outcome.

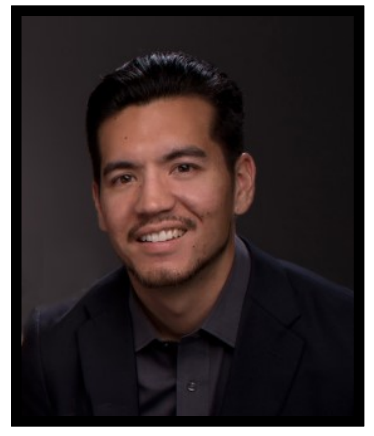

Joshua Fisher has nearly a decade of experience with youth leadership development work. With a MA in Higher Education concentrating in Diversity and Social Justice from the University of Michigan, Joshua has been able to advance his practice in working with students to identify and meet their life goals. Formally the Assistant Director of Leadership in student activities at the University of California Santa Cruz, he now serves as the Interim Project Director of Asian Pacific Islander Youth Promoting Advocacy and Leadership (AYPAL), a high school youth organizing focused organization in his hometown of Oakland, CA. 


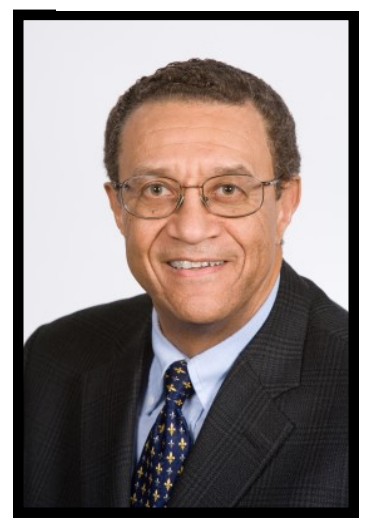

William Collins is currently Executive Director of the Center for Educational Outreach at the University of Michigan. From 1992-2008, he served as Director of the Comprehensive Studies Program and as Adjunct Associate Professor of Psychology at the University of Michigan as well. He has previously served as the Director of the Learning Skills Center at Cornell University and as Staff Psychologist and Assistant Professor of Psychology at the University of Wisconsin-Stevens Point.

A native of Detroit, Michigan, Collins earned his bachelor's degree and his Ph.D. in Psychology from the University of Michigan. He is a member of the Association for Psychological Science, the Society for Personality and Social Psychology, and the Society for the Psychological Study of Social Issues. He is also a member of the Executive Committee of the Council on Engagement of the Association of Public and Land Grant Universities.

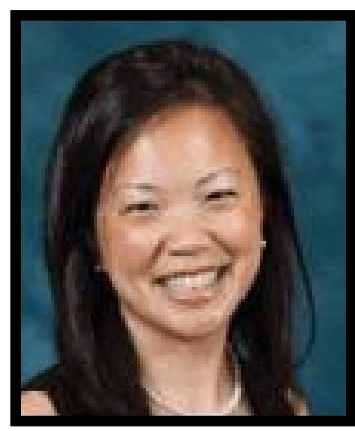

Marie P. Ting is the Associate Director of the National Center for Institutional Diversity at the University of Michigan. She earned her bachelor's degree in psychology and a master's degree in higher education from the University of Michigan, and her doctorate in higher education policy and leadership from the University of Maryland. Marie joined the NCID after serving as a program manager at the University of Michigan's Center for Educational Outreach (CEO). Prior to returning to the University of Michigan, Marie served as university director of student affairs and special programs at the City University of New York (CUNY). She has also held positions in academic and student affairs at the University of Maryland and the University of Michigan. 


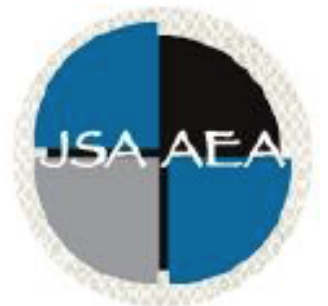

Volume 10 (2015)

\section{Journal of Southeast Asian American Education and Advancement}

\author{
www.JSAAEA.org
}

\section{Editor}

Dr. Wayne E. Wright

Purdue University

\section{Associate Editors}

Dr. Chhany Sak-Humphry

University of Hawaii at Manoa

Dr. Phitsamay Sychitkokhong Uy

University of Massachusetts, Lowell

\section{Book Review Editor}

Dr. Vichet Chhuon

University of Minnesota

\section{Creative Works Editor \\ Bryan Thao Worra \\ Lao Assistance Center}

\section{Journal Manager \\ Marshall Klassen \\ Purdue University}

\section{Editorial Review Board}

\author{
Dr. Steve Arounsack \\ California State University, Stanislaus \\ Dr. Sovicheth Boun \\ The State University of New York at Fredonia \\ Dr. George Chigas \\ University of Massachusetts, Lowell \\ Dr. Hien Duc Do \\ San Jose State University \\ Dr. Sophal Ear \\ Occidental College \\ Dr. Jeremy Hein \\ University of Wisconsin, Eau Claire
}

\author{
Dr. Carl L. Bankston III \\ Tulane University \\ Dr. Phala Chea \\ Lowell Public Schools \\ Dr. Loan Dao \\ University of Massachusetts, Boston \\ Dr. Changming Duan \\ University of Missouri, Kansas City \\ Dr. Sothy Eng \\ Lehigh University \\ Dr. Vincent K. Her \\ University of Wisconsin, Eau Claire
}

\footnotetext{
@

SDRERIGHISRESERVEDReaders are free to copy, display, and distribute this article, as long as the work is attributed to the author(s) and the Journal of Southeast Asian American Education \& Advancement, it is distributed for non-commercial purposes only, and no alteration or transformation is made in the work. More details of this Creative Commons license are available at http://creativecommons.org/licenses/by-nc-nd/3.0/. All other uses must be approved by the author(s) or JSAAEA.

Journal of Southeast Asian American Education \& Advancement, Vol. 10 (2015) ISSN: 2153-8999
} 


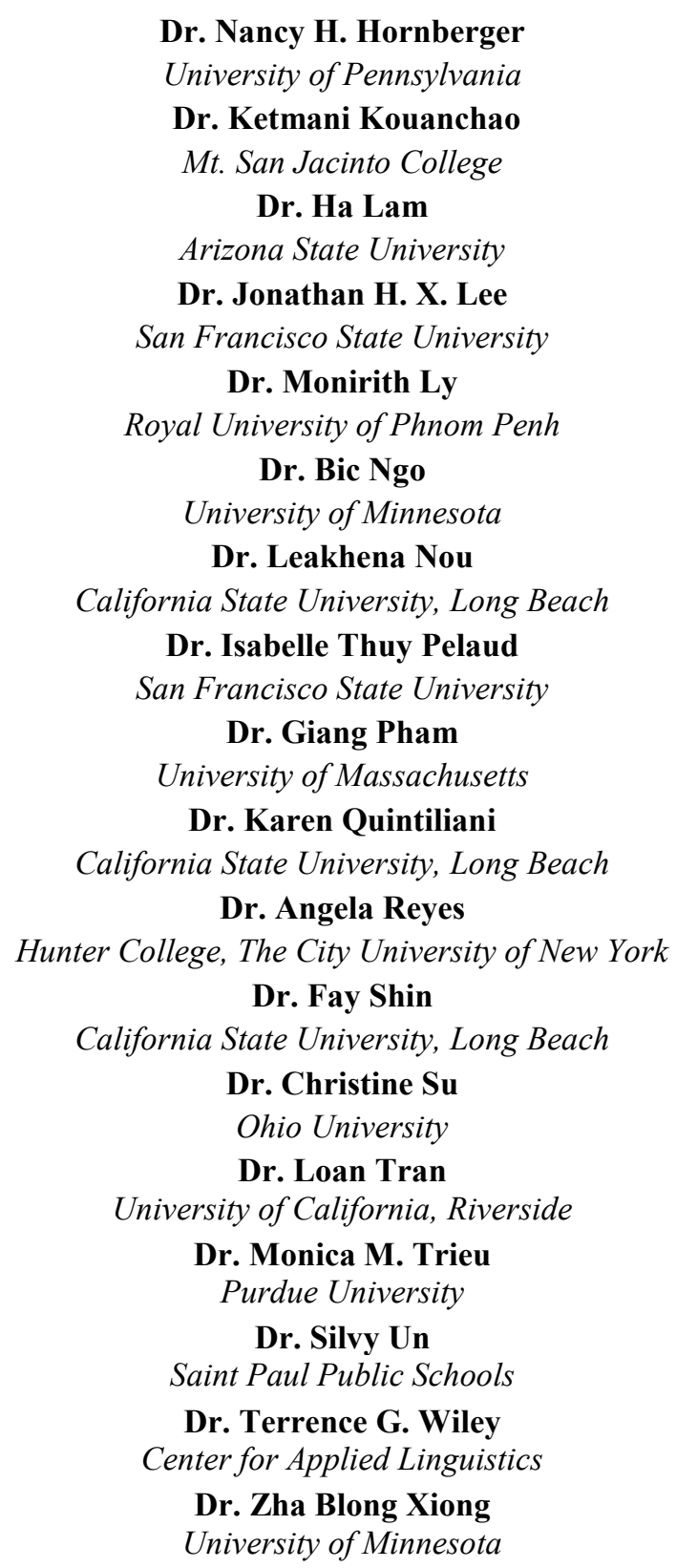

\author{
Dr. Peter Nien-Chu Kiang \\ University of Massachusetts, Boston \\ Dr. Kevin K. Kumashiro \\ University of San Francisco \\ Dr. Ravy Lao \\ California State University, Los Angeles \\ Dr. Stacey Lee \\ University of Wisconsin, Madison \\ Dr. Sue Needham \\ California State University, Dominguez Hills \\ Dr. Max Niedzwiecki \\ Daylight Consulting Group \\ Dr. Clara Park \\ California State University, Northridge \\ Dr. Mark Pfeifer \\ SUNY Institute of Technology \\ Dr. Loan T. Phan \\ University of New Hampshire \\ Dr. Kalyani Rai \\ University of Wisconsin, Milwaukee \\ Dr. Cathy J. Schlund-Vials \\ University of Connecticut, Storrs \\ Dr. Nancy J. Smith-Hefner \\ Boston University \\ Dr. Yer J. Thao \\ Portland State University \\ Dr. Tinou Tran \\ Alief Independent School District \\ Dr. Khatharya Um \\ University of California, Berkeley \\ Dr. Linda Trinh Vo \\ University of California, Irvine \\ Dr. Yang Sao Xiong \\ University of Wisconsin-Madison \\ Dr. Kou Yang \\ California State University, Stanislaus
}

\section{Doctoral Student Editorial Review Board}

\author{
Virak Chan \\ University of Texas at San Antonio \\ Annie BichLoan Duong \\ San Joaquin County Office of Education \\ Minh Mai \\ University of Wisconsin-Madison \\ Hoa Nha Nguyen \\ Boston College \\ Malaphone Phommasa \\ University of California, Santa Barbara
}

\author{
Keo Chea-Young \\ University of Pennsylvania \\ Peter Tan Keo \\ Columbia University \\ Dung Minh Mao \\ University of Minnesota \\ Thien-Huong Ninh \\ University of Southern California \\ Alisia Tran \\ University of Minnesota
}

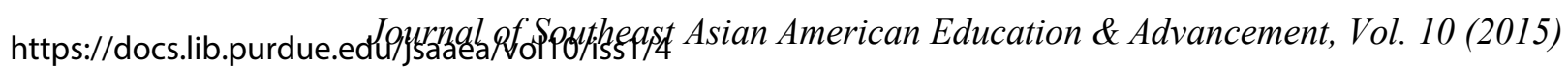




\author{
Krissyvan Truong \\ Claremont Graduate University \\ Soua Xiong \\ San Diego State University \& Claremont \\ Graduate University
}

\author{
Molly Wiebie \\ The University of Texas at Austin \\ Anna H. Yang \\ University of Georgia
}

\author{
Lesley Yang \\ University of Minnesota
}

Journal of Southeast Asian American Education \& Advancement, Vol. 10 (2015) 